\title{
Short- and long-term effects of various Citrullus colocynthis seed extracts in normal and streptozotocin-induced diabetic rats
}

\author{
NABILA BENARIBA ${ }^{1,2}$, RABEH DJAZIRI $^{1}$, BOUCHRA HANANE ZERRIOUH $^{1}$, \\ WAFAA BELLAKHDAR ${ }^{1}$, EMELINE HUPKENS ${ }^{2}$, ZAHIA BOUCHERIT ${ }^{1}$ and WILLY J. MALAISSE ${ }^{2}$ \\ ${ }^{1}$ Laboratory of Antibiotic and Antifungal Physico-Chemistry, Synthesis and Biological Activity, \\ Faculté des Sciences, University Abou Bekr Belakaïd, Tlemcen, Algeria; ${ }^{2}$ Laboratory of \\ Experimental Hormonology, Université Libre de Bruxelles, Brussels, Belgium
}

Received July 4, 2012; Accepted August 22, 2012

DOI: $10.3892 /$ ijmm.2012.1127

\begin{abstract}
In the light of previous findings, the major aim of the present study was to investigate the potential beneficial effects of various Citrullus colocynthis L. seed extracts on such variables as glucose tolerance, body weight gain, pancreas, liver, kidney, testis, epididymal fat and diaphragm muscle weight, as well as serum cholesterol, triglyceride, urea, creatinine, transaminases and alkaline phosphatase concentrations in an animal model of type-1 diabetes mellitus, i.e. streptozotocin-induced diabetic rats. For purpose of comparison, a comparable study was conducted in normal rats. Both the immediate and long-term effects of the plant extracts were assessed in rats injected daily, up to 3 weeks after the start of the experiments. The results of this study reinforce the view that both a crude aqueous extract and a n-butanol extract from the Citrullus colocynthis L. seeds may represent the best candidates in order to eventually identify a component suitable for the treatment of both type- 1 and type- 2 diabetic subjects.
\end{abstract}

\section{Introduction}

Several reports were recently published on the potential beneficial effects of Citrullus colocynthis extracts in animal models of diabetes mellitus (1-4). In light of these previous findings, the present study aimed mainly at assessing the effects of five distinct extracts from Citrullus colocynthis seeds, i.e. a crude and a defatted aqueous extract, an $\mathrm{H}_{2} \mathrm{O}$-methanol extract, an ethyl acetate extract and a n-butanol extract on a number of metabolic variables in streptozotocin-induced diabetic rats. For the purpose of comparison, a comparable study was conducted

Correspondence to: Professor Willy J. Malaisse, Laboratory of Experimental Hormonology, Université Libre de Bruxelles, 808 Route de Lennik, B-1070 Brussels, Belgium

E-mail: malaisse@ulb.ac.be

Key words: streptozotocin-induced diabetic rats, Citrullus colocynthis seed extracts, glucose homeostasis, body weight gain, serum cholesterol and triglyceride concentration in normal rats, whilst a further group of STZ rats was exposed to glibenclamide. Both the short-term effects recorded over $180 \mathrm{~min}$ after the first intraperitoneal injection of each tested material and the long-term effects observed after daily injection up to three weeks after the onset of the experiments were examined in the present study.

\section{Materials and methods}

Fresh fruit of Citrullus colocynthis were collected from desert area of Aïn sefra (Algeria). The species was botanically authenticated. A voucher specimen of the plant is deposited in the herbarium of the Laboratory of Ecology. Box Cucurbitaceae. Code 2686 (University Es Senia-Oran, Algeria). Five extracts from Citrullus colocynthis seeds were used in the present experiments, namely a crude untreated aqueous extract, a defatted aqueous extract, an $\mathrm{H}_{2} \mathrm{O}$-methanol extract, an ethyl acetate extract and a n-butanol extract. The aqueous extracts of Citrullus colocynthis L. seeds were prepared as described elsewhere (2). For the hydromethanolic extract, $50 \mathrm{~g}$ of seeds were ground and degreased in hexane. This material was heated and stirred 3 times for $3 \mathrm{~h}$ in water:methanol mixture (30:70). Then, after filtration and centrifugation, the recovered solution was divided into two volumes; one was evaporated to dryness and provided a hygroscopic red-orange residue $\left(\mathrm{H}_{2} \mathrm{O}\right.$-methanol extract; $4.5 \%$ dry matter). The second volume was used, after liquid-liquid extraction 3 times with ethyl acetate and n-butanol respectively, for the preparation of the ethyl acetate (orange powder $1.1 \%$ dry matter) and n-butanol (brown powder $1.2 \%$ dry matter) extracts.

Male Wistar rats weighing $208 \pm 3 \mathrm{~g}(\mathrm{n}=72)$ at the onset of the present experiments were given free access to tap water and a commercial diet containing (w/w) $49.5 \%$ carbohydrate, $15.7 \%$ protein and $7.8 \%$ lipid. Forty-two of these rats were injected intraperitoneally with streptozotocin $(65 \mathrm{mg} / \mathrm{kg}$ body $\mathrm{wt}$.) dissolved in a citrate buffer (0.1 M, pH 4.5) one week before the onset of the experiments after overnight starvation.

A first blood sample was obtained on day zero after overnight fasting by puncture of the retro-orbital sinus. The animals were then injected intraperitoneally either with saline $(5 \mathrm{ml} / \mathrm{kg})$, glibenclamide $(10 \mathrm{mg} / \mathrm{kg})$, the crude or defatted aqueous extract $\left(90 \mathrm{mg} / \mathrm{kg}\right.$ ), the $\mathrm{H}_{2} \mathrm{O}$-methanol extract $(100 \mathrm{mg} / \mathrm{kg}$ ), the ethyl 
Table I. Glycemia (mM) in short-term experiments.

\begin{tabular}{|c|c|c|c|c|c|c|}
\hline Rats & Extract & Zero & $30 \mathrm{~min}$ & $60 \mathrm{~min}$ & $120 \mathrm{~min}$ & $180 \mathrm{~min}$ \\
\hline \multirow[t]{6}{*}{ Normal } & Control & $5.43 \pm 0.28(5)$ & $6.02 \pm 0.14(5)$ & $6.87 \pm 0.29$ (5) & $5.56 \pm 0.23(5)$ & $5.77 \pm 0.27(5)$ \\
\hline & Untreated aqueous & $5.34 \pm 0.10$ & $6.39 \pm 0.34(5)$ & $6.49 \pm 0.09(5)$ & $5.90 \pm 0.22(5)$ & $5.60 \pm 0.31(5)$ \\
\hline & Defatted aqueous & $5.27 \pm 0.18$ & $6.55 \pm 0.26(5)$ & $7.08 \pm 0.41(5)$ & $6.07 \pm 0.23(5)$ & $5.00 \pm 0.23$ \\
\hline & $\mathrm{H}_{2} \mathrm{O}$-methanol & $5.02 \pm 0.34(5)$ & $5.08 \pm 0.40(5)$ & $6.51 \pm 0.21(5)$ & $5.34 \pm 0.33(5)$ & $4.64 \pm 0.41(5)$ \\
\hline & Ethyl acetate & $5.41 \pm 0.16(5)$ & $6.62 \pm 0.48(5)$ & $6.79 \pm 0.72(5)$ & $6.43 \pm 0.58(5)$ & $6.63 \pm 0.59(5)$ \\
\hline & n-butanol & $5.06 \pm 0.14$ & $5.36 \pm 0.22(5)$ & $5.61 \pm 0.14(5)$ & $5.83 \pm 0.34(5)$ & $5.48 \pm 0.36(5)$ \\
\hline \multirow[t]{7}{*}{ STZ } & Control & $21.32 \pm 1.26(7)$ & $26.44 \pm 0.54(7)$ & $28.25 \pm 0.49(7)$ & $29.13 \pm 1.04(7)$ & $28.33 \pm 1.09(7)$ \\
\hline & Glibenclamide & $22.01 \pm 1.04(10)$ & $23.75 \pm 1.42(10)$ & $21.13 \pm 1.73(10)$ & $19.54 \pm 1.38(10)$ & $17.81 \pm 1.36(10)$ \\
\hline & Untreated aqueous & $19.03 \pm 0.55(5)$ & $22.32 \pm 1.02(5)$ & $23.82 \pm 0.69(5)$ & $22.52 \pm 0.97(5)$ & $22.71 \pm 1.15(5)$ \\
\hline & Defatted aqueous & $20.00 \pm 0.82(5)$ & $25.32 \pm 0.68$ & $24.26 \pm 1.27(5)$ & $20.30 \pm 1.00(5)$ & $19.26 \pm 0.87(5)$ \\
\hline & $\mathrm{H}_{2} \mathrm{O}$-methanol & $18.52 \pm 1.46(5)$ & $18.43 \pm 1.56(5)$ & $20.91 \pm 2.96(5)$ & $22.89 \pm 2.40(5)$ & $24.69 \pm 3.12(5)$ \\
\hline & Ethyl acetate & $17.06 \pm 2.50$ & $19.86 \pm 2.64(5)$ & $21.42 \pm 2.80(5)$ & $22.48 \pm 3.46(5)$ & $21.12 \pm 1.62(5)$ \\
\hline & n-butanol & $16.38 \pm 0.26(5)$ & $17.37 \pm 0.46(5)$ & $17.91 \pm 1.34(5)$ & $15.98 \pm 1.36(5)$ & $12.49 \pm 1.21(5)$ \\
\hline
\end{tabular}

acetate extract $(10 \mathrm{mg} / \mathrm{kg})$ or the n-butanol extract $(70 \mathrm{mg} / \mathrm{kg})$. Further blood samples were obtained from the tail tip 30,60, 120 and 180 min after such an intraperitoneal injection (shortterm experiments).

The same rats were then injected daily over a period of 3 weeks with the same material always administered intraperitoneally. Blood samples were obtained after overnight starvation by retro-orbital puncture on day 7, day 14 and day 21 (long-term experiments). An oral glucose tolerance test was then performed, a solution of D-glucose being administered by a gastric sound to deliver $2.0 \mathrm{~g}$ of D-glucose per kg body wt. and blood samples being collected from the tail tip 30, 60, 120 and $180 \mathrm{~min}$ thereafter. The next day (day 22), the rats were sacrificed under chloral anesthesia after overnight starvation and the pancreas, liver, kidneys, testes, epididymal adipose tissue and diaphragm muscle removed and weighed.

The glycemia was measured in blood samples using a glucometer (Accu-check). The serum concentration of cholesterol, triglycerides and urea were measured by enzymatic Kit Spinreact, S.A. Ctra. Santa Coloma, Sant Esteve de Bas (GI) Spain; creatinine is measured by end point Jaffé method (Kit Prochima, Prochima Sigma, Sarl, Tlemcen, Algeria), glutamate-pyruvate and glutamate-oxaloacetate transaminase and alkaline phosphatase were measured by enzymatic Kit Spinreact, S.A. Ctra. Santa Coloma.

All results, including those already mentioned, are presented as mean values $( \pm$ SEM) together with the number of individual observations (n). The statistical significance of differences between mean values was assessed by use of Student's t-test.

\section{Results}

Short-term experiments. In the short-term experiments, overnight fasted rats were injected intraperitoneally with various extracts, their glycemia being measured before and at intervals after such an injection. The primary results of these experiments are listed in Table I. As expected, the initial

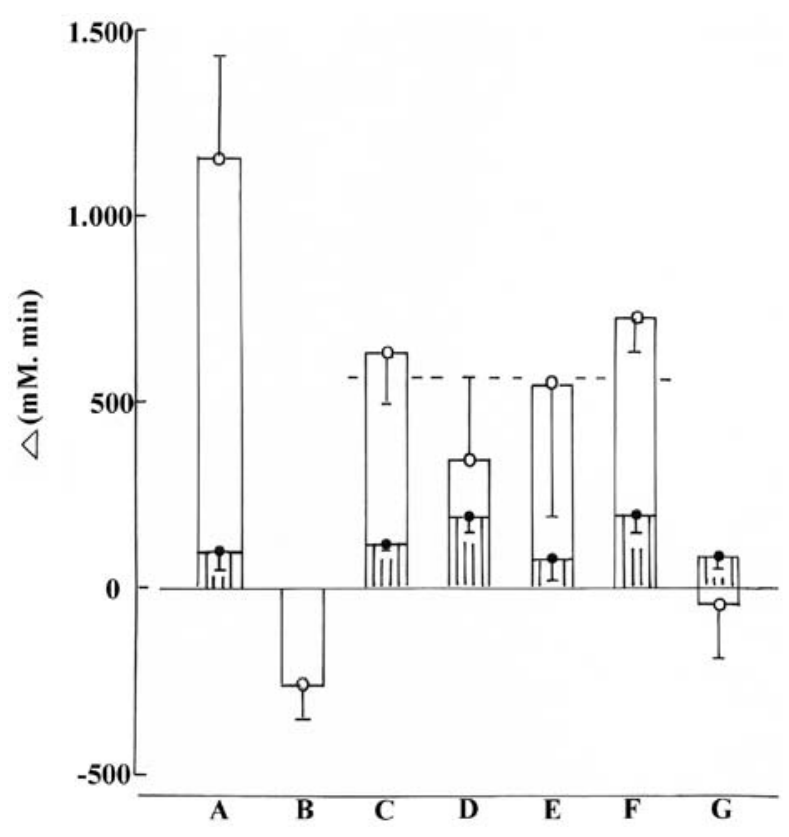

Figure 1. Incremental or decremental changes $(\Delta)$ in glycemia over $180 \mathrm{~min}$ after administration of saline (A), glibenclamide (B), the untreated aqueous extract $(C)$, the defatted aqueous extract (D), the $\mathrm{H}_{2} \mathrm{O}$-methanol extract (E), the ethyl acetate extract $(\mathrm{F})$ or the n-butanol extract $(\mathrm{G})$ to either normal rats (closed circles and hatched columns) or STZ rats (open circles and open columns). Mean values ( \pm SEM) refer to 5-10 individual experiments. The horizontal dashed line refers to the overall mean value found in the STZ rats of the C, D, E and F groups.

measurements of glycemia yielded a much higher mean value $(\mathrm{p}<0.001)$ in STZ rats $(19.62 \pm 0.55 \mathrm{mM} ; \mathrm{n}=42)$ than in normal animals $(5.25 \pm 0.09 \mathrm{mM} ; \mathrm{n}=30)$. In order to assess the overall changes in glycemia, the incremental (or decremental) area was calculated in each individual experiment. As illustrated in Fig. 1, in the normal animals, no significant difference was observed ( $p>0.19$ or more) for such an incremental area between control rats and any of the five experimental groups. In the control animals injected with saline, the incremental area was significantly higher $(\mathrm{p}<0.01)$ in the STZ 
Table II. Glycemia (mM) in long-term experiments.

\begin{tabular}{llrrrr}
\hline Rats & \multicolumn{1}{c}{ Extract } & Day zero & Day 7 & Day 14 & Day 21 \\
\hline Normal & Control & $5.43 \pm 0.28(5)$ & $5.14 \pm 0.21(5)$ & $5.07 \pm 0.21(5)$ & $5.02 \pm 0.14(5)$ \\
& Untreated aqueous & $5.34 \pm 0.10(5)$ & $5.01 \pm 0.19(4)$ & $5.43 \pm 0.07(4)$ & $5.56 \pm 0.23(3)$ \\
& Defatted aqueous & $5.27 \pm 0.18(5)$ & $4.62 \pm 0.27(5)$ & $4.94 \pm 0.15(5)$ & $4.43 \pm 0.24(5)$ \\
& He-methanol & $5.02 \pm 0.34(5)$ & $4.90 \pm 0.24(5)$ & $4.70 \pm 0.29(5)$ & $5.16 \pm 0.17(5)$ \\
& Ethyl acetate & $5.41 \pm 0.16(5)$ & $4.83 \pm 0.25(5)$ & $5.01 \pm 0.17(5)$ & $4.92 \pm 0.11(5)$ \\
STZ & n-butanol & $5.06 \pm 0.14(5)$ & $5.17 \pm 0.15(5)$ & $5.46 \pm 0.14(5)$ & $5.16 \pm 0.34(5)$ \\
& Control & $21.32 \pm 1.26(7)$ & $19.41 \pm 2.54(7)$ & $25.19 \pm 2.11(7)$ & $21.44 \pm 0.95(7)$ \\
& Glibenclamide & $22.01 \pm 1.04(10)$ & $13.77 \pm 1.40(6)$ & $14.17 \pm 3.04(5)$ & $13.40 \pm 3.97(5)$ \\
& Untreated aqueous & $19.03 \pm 0.55(5)$ & $11.70 \pm 1.14(5)$ & $13.09 \pm 3.03(5)$ & $7.98 \pm 1.38(5)$ \\
& Defatted aqueous & $20.00 \pm 0.82(5)$ & $15.79 \pm 2.07(5)$ & $18.14 \pm 2.85(4)$ & $25.98 \pm 2.51(3)$ \\
& Ho-methanol & $18.52 \pm 1.46(5)$ & $15.94 \pm 1.76(4)$ & $6.93 \pm 1.32(4)$ & $7.02 \pm 1.84(3)$ \\
& Ethyl acetate & $17.06 \pm 2.50(5)$ & $18.97 \pm 3.11(5)$ & $10.91 \pm 5.33(5)$ & $9.85 \pm 3.64(4)$ \\
& n-butanol & $16.38 \pm 0.26(5)$ & $11.17 \pm 1.21(5)$ & $10.98 \pm 1.65(5)$ & $9.04 \pm 0.97(5)$ \\
\hline
\end{tabular}

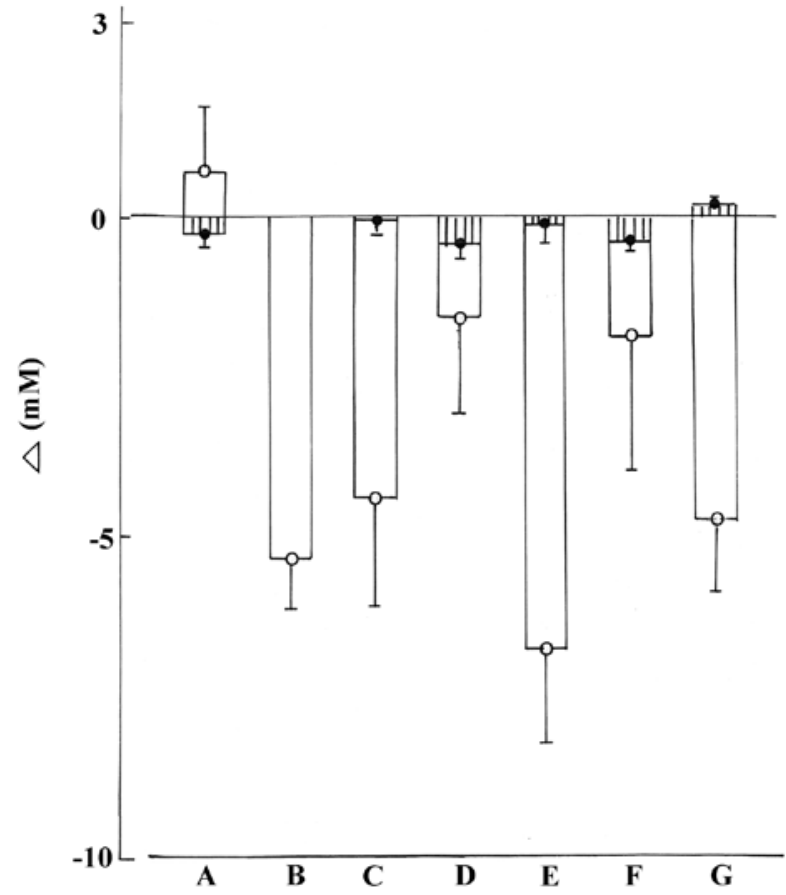

Figure 2. Incremental or decremental change $(\Delta)$ in glycemia, as judged from the area above or below the day zero value, during a period of 3 weeks in either normal rats (closed circles and hatched columns) or STZ rats (open circles and open columns) injected daily with saline (A), glibenclamide (B), the untreated aqueous extract (C), the defatted aqueous extract (D), the $\mathrm{H}_{2} \mathrm{O}$ methanol extract $(\mathrm{E})$, the ethyl acetate extract $(\mathrm{F})$ or the n-butanol extract $(\mathrm{G})$. Mean values ( \pm SEM) refer to 4-7 individual experiments.

rats $(1,156 \pm 275 \mathrm{mM} . \mathrm{min} ; \mathrm{n}=7)$ than in the normal animals $(99 \pm 48$ mM.min; $n=5)$. In the STZ rats injected with glibenclamide, a decremental area $(-258 \pm 97$ mM.min; $\mathrm{n}=5 ; \mathrm{p}<0.03)$ prevailed, as distinct from the incremental area recorded in the control STZ rats. In the STZ rats injected with the n-butanol extract, the mean area below time zero value $(-42 \pm 145$ mM.min; $n=5)$ was also significantly lower $(p<0.008)$ than the mean incremental area found in the control STZ rats. Although such was no more the case in the other four groups of experimental STZ rats, which yielded mean values not significantly different from one another ( $p>0.15$ or more), the overall mean incremental area recorded in these four groups $(566 \pm 109 \mathrm{mM}$. min; $n=20)$ was again significantly lower $(\mathrm{p}<0.025)$ than that found in the control STZ rats (Fig. 1).

\section{Long-term experiments}

Glycemia. The same animals as those used in the short-term experiments were injected daily for 3 weeks with the different extracts, the glycemia being measured on day 7, 14 and 21 after overnight starvation. The primary data collected in these long-term experiments are listed in Table II. The overall changes in glycemia over this 3-week period were assessed by calculating, in each individual experiment, the incremental (or decremental) area above (or below) the day zero measurement. As documented in Fig. 2, in the normal rats, such incremental (or decremental) area yielded mean values not significantly different ( $p>0.09$ or more) in the control animals and in the five groups of experimental rats.

As judged from the incremental (or decremental) area, no significant difference ( $p>0.47)$ was observed between the mean increment in glycemia over the 3 weeks period in the control STZ rats $(+0.68 \pm 1.04 \mathrm{mM} ; \mathrm{n}=7)$ and the mean decrement in glycemia over the same period in the control normal rats $(-0.28 \pm 0.23 \mathrm{mM} ; \mathrm{n}=5)$. Except in the STZ rats injected with either the defatted aqueous extract $(p>0.22)$ or ethyl acetate extract $(\mathrm{p}>0.26)$, the mean decreases in glycemia were significantly different ( $p<0.007$ or less) in the experimental STZ rats from the mean increment recorded in the control STZ rats (Fig. 2).

Oral glucose tolerance test (OGTT). The vastly different pattern of the OGTT in the control normal and STZ rats is illustrated in the left panel of Fig. 3. In the normal rats, there was little to distinguish between the 6 groups of animals in terms of the time zero values for glycemia at the onset of the OGTT. Nevertheless, the area under the curve (AUC) was 

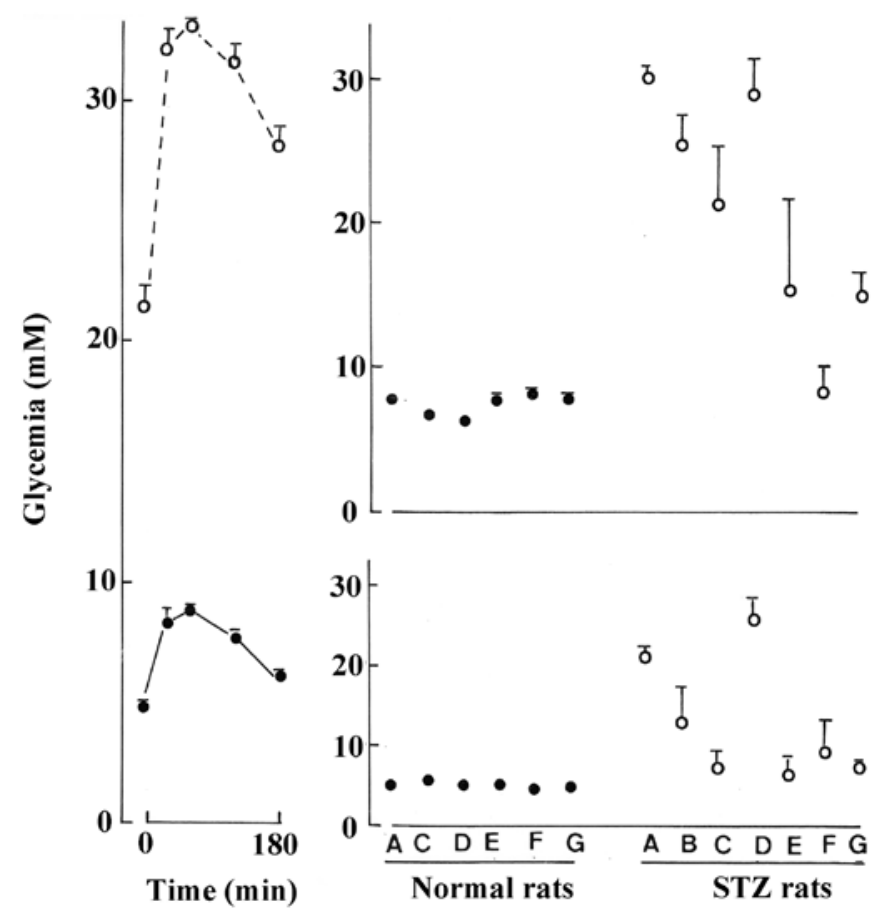

Figure 3. Left panel: time course for changes in glycemia during the OGTT performed in control normal rats (closed circles and solid line) and control STZ rats (open circles and dashed line). Right panels: time zero glycemia during the IPGTT (lower right panel) and mean glycemia, as judged from the AUC (upper right panel) in either normal rats (closed circles) or STZ rats (open circles) injected with saline (A), glibenclamide (B), the untreated aqueous extract (C), the defatted aqueous extract (D), the $\mathrm{H}_{2} \mathrm{O}$-methanol extract (E), the ethyl acetate extract (F) or the n-butanol extract (G). Mean values ( \pm SEM) refer to 3-7 individual experiments.

significantly lower in the normal rats injected with either the untreated aqueous extract $(\mathrm{p}<0.01)$ or defatted aqueous extract $(\mathrm{p}<0.001)$ than in the control normal rats. Such was not the case in the normal rats injected with either the $\mathrm{H}_{2} \mathrm{O}$-methanol extract $(p>0.56)$, ethyl acetate extract $(p>0.61)$ or $n$-butanol extract ( $>0.73$ ). In the seven groups of STZ rats, obvious differences between control and experimental animals were observed whether for the time zero values for glycemia or AUC during the OGTT. As a matter of fact, there was a significant positive correlation $(\mathrm{r}=+0.7912 ; \mathrm{n}=7 ; \mathrm{p}<0.04)$ between the mean values for the latter two variables in the seven groups of STZ rats. Except in the STZ rats injected with the defatted aqueous extract, the mean values for the time zero glycemia were significantly lower ( $p<0.05$ or less) in the experimental groups of STZ rats than in the control STZ rats. Likewise, except in the STZ rats injected with the defatted aqueous extract, the mean values for the AUC during the OGTT were significantly lower ( $<<0.02$ or less) in the experimental groups of STZ rats than in the control STZ rats (Fig. 3, right panels).

Body weight. The body weight of the control normal rats progressively increased ( $\mathrm{n}=5$ in all cases) from $201.5 \pm 1.8 \mathrm{~g}$ to $214.0 \pm 2.1 \mathrm{~g}, 226.3 \pm 3.6 \mathrm{~g}$ and $236.5 \pm 3.5 \mathrm{~g}$, respectively one, two and three weeks after the start of the experiments (Fig. 4). The day 21 minus day zero paired difference in body weight failed to differ significantly in the control normal rats $(34.9 \pm 4.3 \mathrm{~g}$; $\mathrm{n}=5$ ) and the normal rats injected with either the untreated aqueous extract $(25.2 \pm 4.2 \mathrm{~g} ; \mathrm{n}=4)$, the $\mathrm{H}_{2} \mathrm{O}$-methanol extract

$(18.3 \pm 7.8 \mathrm{~g} ; \mathrm{n}=5)$, the ethyl acetate extract $(35.0 \pm 5.2 \mathrm{~g} ; \mathrm{n}=5)$ or the n-butanol extract $(32.2 \pm 7.3 \mathrm{~g} ; \mathrm{n}=5)$. Such a paired difference was significantly lower $(\mathrm{p}<0.02)$, however, in the normal rats injected with the defatted aqueous extract $(7.5 \pm 7.5 \mathrm{~g}$; $\mathrm{n}=5)$ than in the control normal rats.

The body weight of the control STZ rats progressively decreased ( $\mathrm{n}=7$ in all cases) from $211.6 \pm 8.2 \mathrm{~g}$ to 201.6 \pm 8.7 , $177.0 \pm 7.5$ and $155.8 \pm 4.9 \mathrm{~g}$, respectively one, two and three weeks after the onset of the experiments, i.e. one week after the administration of STZ. The day 21 minus day zero paired difference in body weight did not differ significantly in the control rats $(-55.8 \pm 4.7 \mathrm{~g} ; \mathrm{n}=7)$ and the STZ rats injected with glibenclamide $(-48.9 \pm 19.6 \mathrm{~g} ; \mathrm{n}=5)$. Likewise, such a decrease in body weight also failed to differ significantly from that found in the control STZ rats in the diabetic animals injected either with the defatted aqueous extract $(-63.3 \pm 6.8 \mathrm{~g} ; \mathrm{n}=3)$ or the $\mathrm{H}_{2} \mathrm{O}$-methanol extract $(-42.3 \pm 13.8 \mathrm{~g} ; \mathrm{n}=3)$. However, the same decrease in body weight did not exceed $-33.7 \pm 6.8 \mathrm{~g}$ $(\mathrm{n}=5),-6.5 \pm 10.6 \mathrm{~g}(\mathrm{n}=4)$ and $-15.0 \pm 4.9 \mathrm{~g}(\mathrm{n}=5)$ in the STZ rats injected with the untreated aqueous extract, ethyl acetate extract and n-butanol extract, respectively, the latter three mean decreases in body weight being significantly less marked ( $p<0.025$ or less) than that recorded in the control STZ rats. 
Table III. Tissue wet weight (mg).

\begin{tabular}{llcccccc}
\hline Rats & \multicolumn{1}{c}{ Extract } & Pancreas & Liver & Kidneys & Testes & $\begin{array}{c}\text { Epididymal } \\
\text { fat }\end{array}$ & $\begin{array}{c}\text { Diaphragm } \\
\text { muscle }\end{array}$ \\
\hline Normal & Control & $733 \pm 51(5)$ & $8,008 \pm 318(5)$ & $1,512 \pm 100(5)$ & $3,882 \pm 149(5)$ & $2,322 \pm 296(5)$ & $514 \pm 29(5)$ \\
& Untreated extract & $575 \pm 91(5)$ & $6,385 \pm 328(5)$ & $1,025 \pm 33(5)$ & $3,540 \pm 120(5)$ & $605 \pm 42(5)$ & $530 \pm 45(5)$ \\
& Defatted aqueous & $754 \pm 78(5)$ & $7,164 \pm 308(5)$ & $1,200 \pm 27(5)$ & $3,397 \pm 74(5)$ & $608 \pm 40(5)$ & $412 \pm 35(5)$ \\
& $\mathrm{H}_{2} \mathrm{O}-$ methanol & $759 \pm 48(5)$ & $10,943 \pm 720(5)$ & $1,693 \pm 67(5)$ & $3,920 \pm 72(5)$ & $1,682 \pm 221(5)$ & $699 \pm 67(5)$ \\
& Ethyl acetate & $730 \pm 90(5)$ & $7,734 \pm 488(5)$ & $1,571 \pm 120(5)$ & $3,708 \pm 146(5)$ & $2,800 \pm 332(5)$ & $781 \pm 62(5)$ \\
& n-butanol & $647 \pm 73(4)$ & $10,083 \pm 615(4)$ & $1,549 \pm 85(4)$ & $3,664 \pm 109(4)$ & $1,625 \pm 417(4)$ & $535 \pm 89(4)$ \\
STZ & Control & $665 \pm 91(5)$ & $7,686 \pm 516(5)$ & $2,059 \pm 112(5)$ & $3,336 \pm 350(5)$ & $66 \pm 14(5)$ & $270 \pm 77(5)$ \\
& Glibenclamide & $505 \pm 37(5)$ & $7,419 \pm 379(5)$ & $2,070 \pm 111(5)$ & $3,675 \pm 231(5)$ & $221 \pm 65(5)$ & $457 \pm 42(5)$ \\
& Untreated aqueous & $635 \pm 42(4)$ & $8,493 \pm 201(4)$ & $1,820 \pm 84(4)$ & $2,743 \pm 142(4)$ & $438 \pm 112(4)$ & $580 \pm 57(4)$ \\
& Defatted aqueous & $820 \pm 35(3)$ & $8,297 \pm 415(3)$ & $1,700 \pm 80(3)$ & $3,247 \pm 113(3)$ & $520 \pm 111(3)$ & $405 \pm 15(2)$ \\
& H O-methanol & $415 \pm 115(2)$ & $7,300 \pm 1,100(2)$ & $2,440 \pm 540(2)$ & $2,680 \pm 790(2)$ & $820 \pm 30(2)$ & $940 \pm 70(2)$ \\
& Ethyl acetate & $578 \pm 136(4)$ & $7,595 \pm 860(4)$ & $2,030 \pm 224(4)$ & $2,755 \pm 546(4)$ & $718 \pm 124(4)$ & $888 \pm 93(4)$ \\
& n-butanol & $628 \pm 37(4)$ & $6,820 \pm 363(4)$ & $1,654 \pm 49(4)$ & $3,139 \pm 253(4)$ & $582 \pm 69(4)$ & $574 \pm 54(4)$
\end{tabular}

Organs weight. As shown in Table III, the mean wet weight of the pancreatic gland did not differ significantly in the control normal rats and in the five other groups of normal rats. Such was also the case in the STZ rats. A significantly difference between normal and STZ rats $(\mathrm{p}<0.02)$ was only observed in the animals injected with the $\mathrm{H}_{2} \mathrm{O}$-methanol extract. As a matter of fact, the pancreatic wet weight averaged, in the STZ rats, $92.5 \pm 5.6 \%(\mathrm{n}=22 ; \mathrm{p}>0.27)$ of the mean corresponding values $(100.0 \pm 4.1 \% ; \mathrm{n}=29)$ found under the same experimental conditions in the normal animals.

The wet weight of the liver was significantly lower $(\mathrm{p}<0.01)$ in the normal rats injected with the untreated aqueous extract than in the control normal rats, whilst being significantly higher ( $\mathrm{p}<0.02$ or less) in the normal rats injected with either the $\mathrm{H}_{2} \mathrm{O}$-methanol or n-butanol extract than in the control animals. In the STZ rats, none of the mean values found in the six experimental groups differed significantly from the mean control value.

In the normal rats, only those animals injected with the untreated or defatted aqueous extract yielded a mean kidneys wet weight significantly different from $(\mathrm{p}<0.02)$, i.e. lower than, that found in the control animals. In the STZ rats, only those animals injected with the $n$-butanol extract displayed a significantly different $(\mathrm{p}<0.02)$, i.e. lower, mean kidney weight than that found in the control STZ rats. A salient finding consisted in the higher weight of the kidneys in the STZ rats than in the normal rats. In the former STZ rats, it averaged $136.6 \pm 6.1 \%$ $(n=22 ; p<0.001)$ of the mean corresponding values found in the normal rats injected with the same material $(100.0 \pm 1.9 \%$; $\mathrm{n}=29)$.

In the normal rats, the wet weight of the testes was lower $(\mathrm{p}<0.01)$ in the rats injected with the defatted aqueous extract than in the control rats. This was the sole significant difference between control and experimental normal rats. No significant difference was observed between the six mean values for testes weight in the experimental STZ rats and the mean value recorded in the control STZ rats. The testes weight of the STZ rats only averaged $82.0 \pm 4.0 \%(n=22 ; \mathrm{p}<0.001)$ of the mean corresponding values found in normal rats injected with the same material $(100.0 \pm 1.2 \% ; \mathrm{n}=29)$.

The wet weight of the epididymal fat was much lower $(p<0.001)$ in the normal rats injected with either the untreated or defatted aqueous extract than in the control normal rats. The difference between the latter control normal rats and the other three groups of normal rats failed to achieve statistical significance. In the STZ rats, all experimental mean values were higher $(\mathrm{p}<0.05$ or less) than the mean control value. The wet weight of the epididymal fat was dramatically lower $(\mathrm{p}<0.001)$ in the control STZ rats $(66 \pm 14 \mathrm{mg} ; \mathrm{n}=5)$ than in the control normal rats $(2,322 \pm 296 \mathrm{mg} ; \mathrm{n}=5)$. In the experimental groups, it also remained lower in the STZ rats than in the normal animals, the mean values recorded in the STZ rats averaging $52.3 \pm 7.5 \%(n=17 ; p<0.001)$ of the mean corresponding values recorded in normal rats injected with the same material $(100.0 \pm 5.4 \%$; $n=24)$.

Last, the wet weight of the diaphragm muscle was higher $(\mathrm{p}<0.05$ or less) in the normal rats injected either with the $\mathrm{H}_{2} \mathrm{O}$-methanol or ethyl acetate extract than in the control normal rats. Likewise, in the STZ rats, the diaphragm weight was higher ( $\mathrm{p}<0.05$ or less) in the rats injected with either the untreated aqueous extract, $\mathrm{H}_{2} \mathrm{O}$-methanol, ethyl acetate or n-butanol extract than in the control STZ rats. As a matter of fact, the values recorded in each group of STZ rats averaged $97.6 \pm 7.5 \%(n=21 ; p>0.76)$ of the corresponding mean values recorded in normal rats $(100.0 \pm 3.1 \%$; $n=29)$, documenting the absence of any obvious difference between normal and STZ animals.

Serum cholesterol. In the normal control rats, no significant correlation $(\mathrm{r}=+0.037 ; \mathrm{n}=20)$ was observed between the serum total cholesterol concentration (g/l) and time (day zero, 7, 14 and 21). Such was also the case in the normal rats injected with either the defatted aqueous extract $(\mathrm{r}=+0.244 ; \mathrm{n}=19$; $\mathrm{p}>0.1), \mathrm{H}_{2} \mathrm{O}$-methanol extract $(\mathrm{r}=+0.275 ; \mathrm{n}=20 ; \mathrm{p}>0.1)$, ethyl 
Table IV. Serum cholesterol and triglyceride concentrations.

Cholesterol (g/l)

\begin{tabular}{|c|c|c|c|c|c|}
\hline \multirow[b]{2}{*}{ Rats } & \multirow[b]{2}{*}{ Extract } & \multicolumn{4}{|c|}{ Cholesterol (g/l) } \\
\hline & & Day 0 & Day 7 & Day 14 & Day 21 \\
\hline \multirow[t]{6}{*}{ Normal } & Control & $1.49 \pm 0.18$ & $1.39 \pm 0.19(5)$ & $1.47 \pm 0.12(5)$ & $1.50 \pm 0.16(5)$ \\
\hline & Untreated aqueous & $1.35 \pm 0.12(5)$ & $1.17 \pm 0.29(5)$ & $0.94 \pm 0.11(5)$ & $0.90 \pm 0.08$ \\
\hline & Defatted aqueous & $1.23 \pm 0.19(5)$ & $1.26 \pm 0.06(5)$ & $1.43 \pm 0.23(5)$ & $1.42 \pm 0.12(5)$ \\
\hline & $\mathrm{H}_{2} \mathrm{O}$-methanol & $1.29 \pm 0.20(5)$ & $1.24 \pm 0.07(5)$ & $1.19 \pm 0.18(5)$ & $1.06 \pm 0.10(5)$ \\
\hline & Ethyl acetate & $1.42 \pm 0.07$ & $1.63 \pm 0.18(5)$ & $1.62 \pm 0.38(5)$ & $1.28 \pm 0.11(4)$ \\
\hline & n-butanol & $1.48 \pm 0.21$ & $1.25 \pm 0.21(5)$ & $1.46 \pm 0.26(5)$ & $1.43 \pm 0.26(5)$ \\
\hline \multirow[t]{8}{*}{ STZ } & Control & $2.24 \pm 0.07(5)$ & $3.29 \pm 0.26(5)$ & $3.67 \pm 0.44(5)$ & $3.55 \pm 0.13(5)$ \\
\hline & Glibenclamide & $2.07 \pm 0.25(10)$ & $2.33 \pm 0.47(6)$ & $2.09 \pm 0.50(5)$ & $2.09 \pm 0.61(5)$ \\
\hline & Untreated aqueous & $1.85 \pm 0.04(5)$ & $1.26 \pm 0.16(5)$ & $1.14 \pm 0.18(5)$ & $1.08 \pm 0.11(4)$ \\
\hline & Defatted aqueous & $1.51 \pm 0.15(5)$ & $1.44 \pm 0.06(5)$ & $1.63 \pm 0.09(4)$ & $1.62 \pm 0.06(3)$ \\
\hline & $\mathrm{H}_{2} \mathrm{O}$-methanol & $2.16 \pm 0.28$ & $2.01 \pm 0.24(4)$ & $1.18 \pm 0.03(4)$ & $0.94 \pm 0.02(2)$ \\
\hline & Ethyl acetate & $2.95 \pm 0.26(5)$ & $3.18 \pm 0.18(5)$ & $3.12 \pm 0.36(5)$ & $3.00 \pm 0.39(5)$ \\
\hline & n-butanol & $1.92 \pm 0.24(5)$ & $1.62 \pm 0.21(5)$ & $1.61 \pm 0.14(5)$ & $1.61 \pm 0.38(4)$ \\
\hline & & \multicolumn{4}{|c|}{ Triglycerides (g/l) } \\
\hline Rats & Extract & Day 0 & Day 7 & Day 14 & Day 21 \\
\hline \multirow[t]{6}{*}{ Normal } & Control & $1.52 \pm 0.10$ & $2.33 \pm 0.10(5)$ & $2.41 \pm 0.21(5)$ & $2.52 \pm 0.23(5)$ \\
\hline & Untreated aqueous & $1.40 \pm 0.12(5)$ & $1.22 \pm 0.13(5)$ & $0.93 \pm 0.14(5)$ & $0.59 \pm 0.10(4)$ \\
\hline & Defatted aqueous & $1.45 \pm 0.14(5)$ & $1.12 \pm 0.13(5)$ & $1.43 \pm 0.21(5)$ & $1.44 \pm 0.13(5)$ \\
\hline & $\mathrm{H}_{2} \mathrm{O}$-methanol & $1.32 \pm 0.10(5)$ & $1.22 \pm 0.10(5)$ & $1.40 \pm 0.11(5)$ & $1.27 \pm 0.15(5)$ \\
\hline & Ethyl acetate & $1.65 \pm 0.16(5)$ & $1.62 \pm 0.10(5)$ & $1.44 \pm 0.14(5)$ & $1.56 \pm 0.25(4)$ \\
\hline & n-butanol & $1.23 \pm 0.08$ & $1.10 \pm 0.09(5)$ & $1.18 \pm 0.12(7)$ & $1.40 \pm 0.19(4)$ \\
\hline \multirow[t]{7}{*}{ STZ } & Control & $2.09 \pm 0.21(5)$ & $2.18 \pm 0.19(5)$ & $1.46 \pm 0.18(5)$ & $1.58 \pm 0.17(5)$ \\
\hline & Glibenclamide & $1.49 \pm 0.11(10)$ & $1.38 \pm 0.20(6)$ & $1.11 \pm 0.11(5)$ & $0.91 \pm 0.03(5)$ \\
\hline & Untreated aqueous & $1.53 \pm 0.35$ & $1.21 \pm 0.18(5)$ & $1.02 \pm 0.19(5)$ & $1.03 \pm 0.16(4)$ \\
\hline & Defatted aqueous & $1.58 \pm 0.15$ & $1.16 \pm 0.13(5)$ & $0.90 \pm 0.12(5)$ & $1.07 \pm 0.08(3)$ \\
\hline & $\mathrm{H}_{2} \mathrm{O}$-methanol & $1.86 \pm 0.06(5)$ & $1.04 \pm 0.01(4)$ & $0.82 \pm 0.06(4)$ & $0.67 \pm 0.05(2)$ \\
\hline & Ethyl acetate & $2.76 \pm 0.36$ & $2.63 \pm 0.18$ (4) & $1.95 \pm 0.16(4)$ & $2.20 \pm 0.10$ \\
\hline & n-butanol & $1.58 \pm 0.17(5)$ & $1.36 \pm 0.14(5)$ & $1.48 \pm 0.18(5)$ & $1.90 \pm 0.18$ \\
\hline
\end{tabular}

acetate extract $(\mathrm{r}=-0.0776 ; \mathrm{n}=19 ; \mathrm{p}>0.1)$ or $\mathrm{n}$-butanol extract $(r=+0.150 ; n=20 ; p>0.1)$. However, in the normal rats injected with the untreated aqueous extract, a highly significant negative correlation $(\mathrm{r}=-0.643 ; \mathrm{n}=19 ; \mathrm{p}<0.005)$ prevailed between the two variables under consideration (Table IV).

In the control STZ rats, the serum total cholesterol contribution reached between day 7 and day 21 an equilibrium value $(3.62 \pm 0.16 ; \mathrm{n}=15)$ significantly higher $(\mathrm{p}<0.001)$ than that recorded on day zero $(2.24 \pm 0.07 ; n=5)$. The latter value was already significantly higher $(p<0.005)$ than that found at the same time in control normal rats. The injection of either glibenclamide, the defatted aqueous extract, the ethyl acetate extract or the n-butanol extract to the STZ rats prevented the further rise in cholesterol concentration otherwise observed in the control STZ rats. Thus, in the former three groups of rats, no significant difference was observed between the day zero values and those recorded thereafter. A significant decrease in cholesterol concentration was even observed over the same 3 weeks period in the STZ rats injected either with the untreated aqueous extract $(\mathrm{r}=-0.6738 ; \mathrm{n}=19 ; \mathrm{p}<0.003)$ or $\mathrm{H}_{2} \mathrm{O}$-methanol extract $(r=-0.7450 ; n=15 ; \mathrm{p}<0.003)$.

Fig. 5 provides a further illustration of the beneficial effects of the various extracts, as well as glibenclamide, on cholesterol concentration in STZ rats. It refers to the mean of all available measurements made between day zero and day 21 in either normal or STZ rats, and emphasizes the closeto-normalization found in STZ rats injected with the untreated or defatted aqueous extracts, $\mathrm{H}_{2} \mathrm{O}$-methanol and n-butanol extracts.

Serum triglycerides. In the control normal rats, the serum triglyceride concentration $(\mathrm{g} / \mathrm{l})$ increased $(\mathrm{p}<0.001)$ from an 


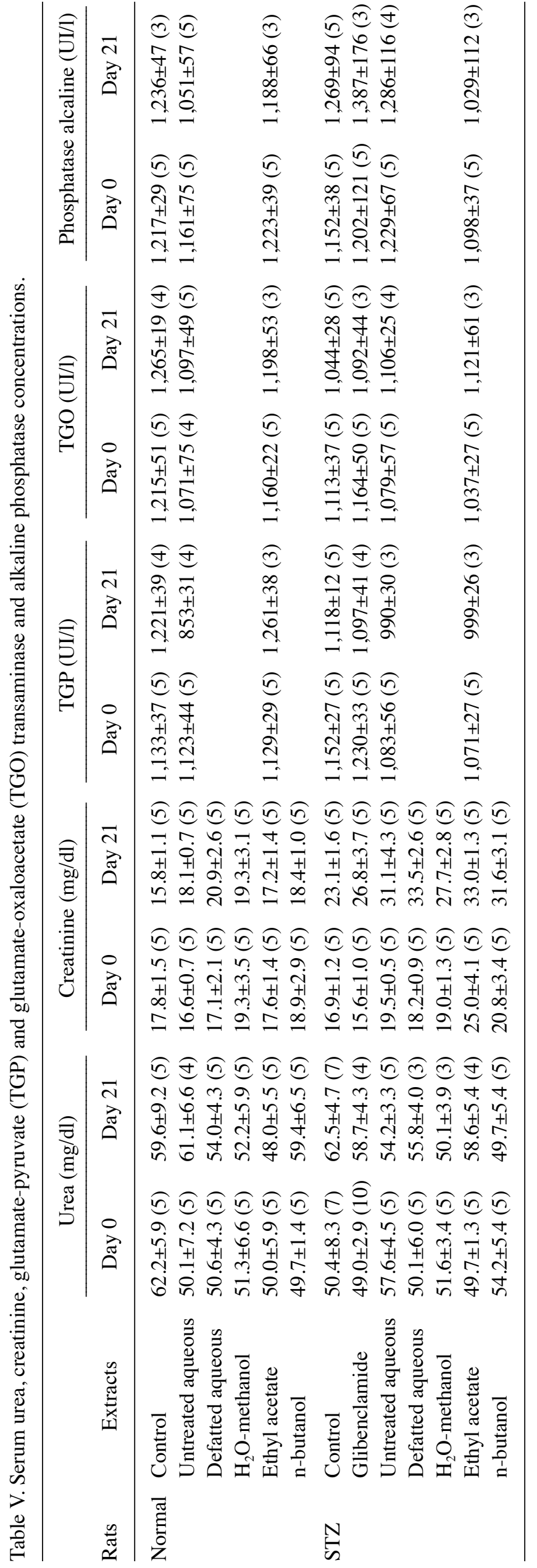

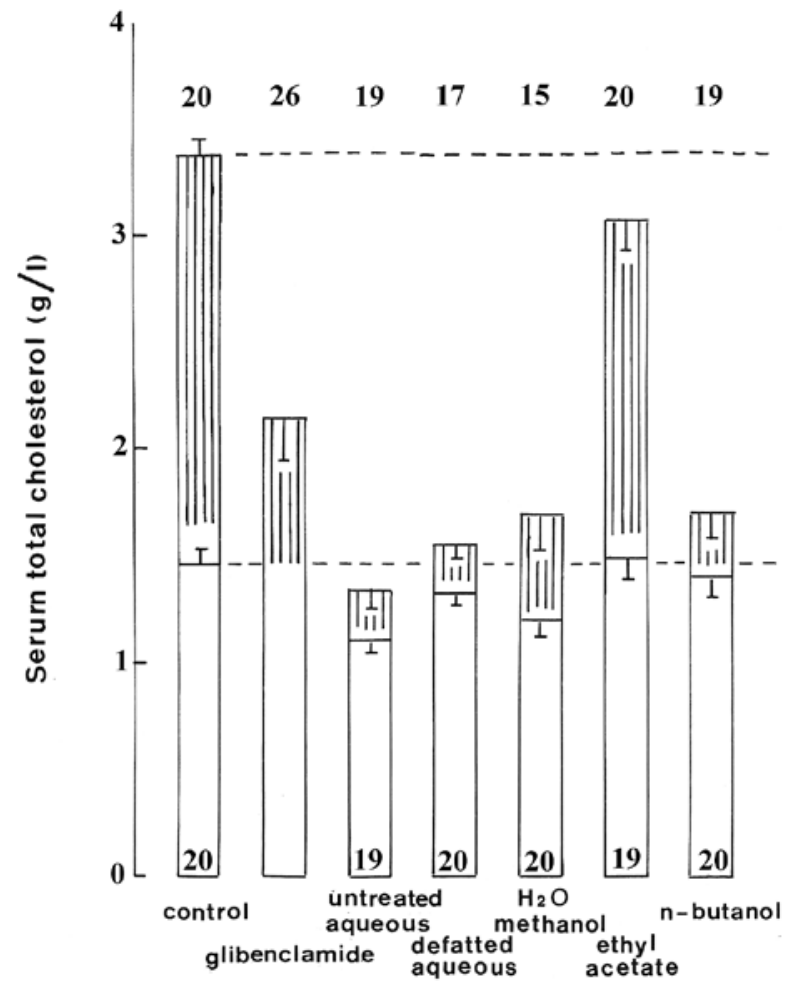

Figure 5. Mean values ( \pm SEM) derived from all available measurements of serum total cholesterol concentration made between day zero and day 21 in either normal rats (open columns) or STZ rats (vertically hatched column) injected with the material indicated below each column. The horizontal dashed lines refer to the mean values found in control animals. The number of individual determinations made in normal and STZ rats are indicated, respectively, at the bottom and above each column.

initial value of $1.52 \pm 0.10(n=5)$ on day zero to a plateau value averaging $2.41 \pm 0.10(n=15)$ during the period of 3 weeks during which these rats were injected daily with saline. Such an increase was not observed in the normal rats injected with either the defatted aqueous extract, $\mathrm{H}_{2} \mathrm{O}$-methanol extract, ethyl acetate extract or n-butanol extract (Table IV). Thus, in the latter four groups, no significant change in serum triglyceride concentration was detected over the same period of 3 weeks. In the normal rats injected with the untreated aqueous extract, a progressive decrease in triglyceride concentration was even observed $(r=-0.506 ; n=19 ; p<0.04)$.

In the control STZ rats, the triglyceride concentration decreased over the 3 weeks period $(r=-0.510 ; n=20 ; p<0.03)$. Except in the STZ rats injected with the n-butanol extract, in which no significant change was recorded over the 3 weeks period $(r=+0.279 ; n=19 ; p>0.1)$, the triglyceride concentration decreased during the same period, whether in the STZ rats injected with glibenclamide $(r=-0.571 ; n=24 ; p<0.04)$, with the untreated or defatted aqueous extract $(\mathrm{r}=-0.458 ; \mathrm{n}=37$; $\mathrm{p}<0.007)$, with the $\mathrm{H}_{2} \mathrm{O}$-methanol extract $(\mathrm{r}=-0.912 ; \mathrm{n}=15$; $\mathrm{p}<0.001)$ or with the ethyl acetate extract $(\mathrm{r}=-0.490 ; \mathrm{n}=16$; $\mathrm{p}<0.06)$. Moreover, except in the STZ rats injected with either the ethyl acetate or n-butanol extract, the mean values recorded at each time point were always lower in the experimental STZ rats than in the control STZ rats (Table IV).

On day zero, i.e. one week after the administration of STZ, the serum triglyceride concentration averaged in the STZ rats $1.80 \pm 0.10(\mathrm{n}=40)$, as distinct $(\mathrm{p}<0.005)$ from $1.43 \pm 0.05(\mathrm{n}=30)$ 


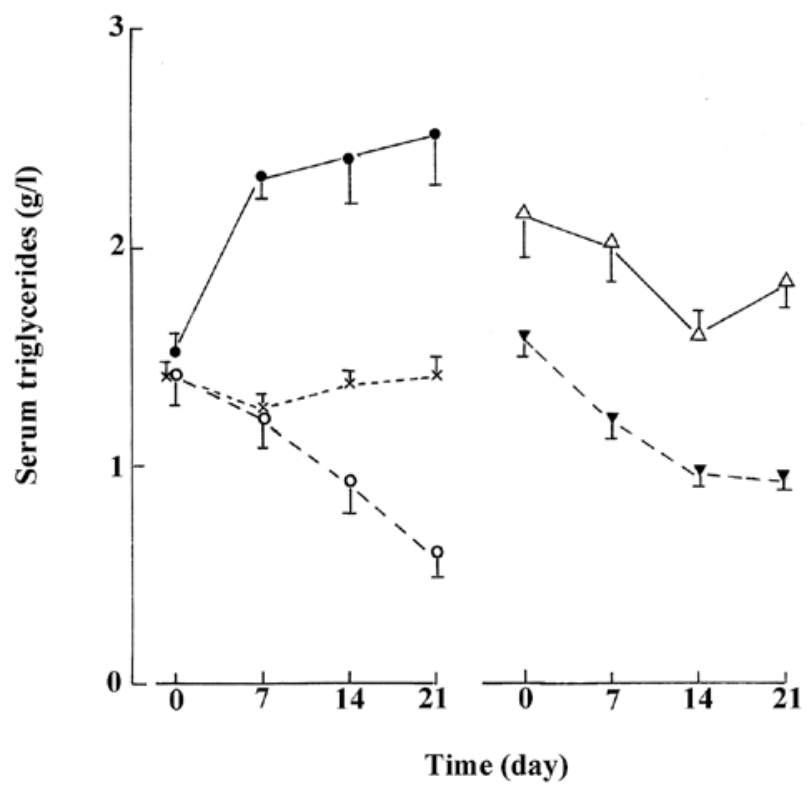

Figure 6. Time course for the changes in serum triglyceride concentration in normal rats (left panel) and STZ rats (right panel). In the left panel, the closed circles and solid line refer to the control normal rats $(n=5)$, the open circles and dashed line to the normal rats injected with the untreated aqueous extract $(n=4-5)$, and the crosses and dotted line to the other experimental groups of normal rats $(n=18-20)$. In the right panel, the open triangles and solid line refer to the control STZ rats and those injected with the ethyl acetate or n-butanol extracts $(n=12-15)$, and the closed triangles and dashed line to the STZ rats injected with glibenclamide, the untreated or defatted aqueous extract, and the $\mathrm{H}_{2} \mathrm{O}$-methanol extract $(\mathrm{n}=14-25)$.

in the normal animals. The patterns of changes recorded thereafter are illustrated in Fig. 6. For instance, in the normal animals, it compares the control group, the rats injected with the untreated aqueous extract, which displayed a progressive decrease in triglyceride concentration, and the four other experimental groups, in which no obvious change in triglyceride concentration was observed. Likewise, in the STZ rats, Fig. 6 compares those groups of rats in which no obvious change in triglyceridemia was observed over the 3-week period, to those groups of rats which displayed a sizeable lowering of triglyceridemia during the same period.

Other serum variables. The serum concentrations of urea, creatinine, glutamate-pyruvate transaminase (TGP), glutamateoxaloacetate transaminase (TGO) and alkaline phosphatase was also measured at the onset (day zero) and end (day 21) of the 3 weeks experimental period (Table V). Two findings merit to be underlined. First, in the normal rats injected with the untreated aqueous extract, the TGP value (UI/l) decreased $(\mathrm{p}<0.003)$ from $1,123 \pm 44(n=5)$ on day zero to $853 \pm 31(n=4)$ on day 21 . Second, in the STZ rats, a striking increase $(\mathrm{p}<0.001)$ in creatinine concentration $(\mathrm{mg} / \mathrm{dl})$ was observed in both control and experimental animals from a mean value of $19.3 \pm 0.8(n=35)$ at day zero to $29.6 \pm 1.1(n=35)$ on day 21 .

\section{Discussion}

In addition to the expected and converging indications of a severe perturbation of glucose homeostasis in the control STZ rats, when compared to the control normal rats and as documented in Tables I and II, as well as in Fig. 3 (left panel), several other striking differences were observed between these two groups of rats. For instance, the control, as well as the experimental, normal rats displayed a progressive increase in body weight, with the opposite situation in control, as well as experimental, STZ rats (Fig. 4). Likewise, the wet weight of the epididymal fat and, to a lesser relative extent that of the testes, was lower in the STZ rats than in the normal animals. Inversely, however, the wet weight of the kidney was higher in the STZ rats than in the normal rats. This coincided with a rise in serum creatinine concentration between day zero and day 21 from $19.3 \pm 0.8$ to $29.6 \pm 1.1 \mathrm{mg} / \mathrm{dl}(\mathrm{n}=35$ in both cases; $\mathrm{p}<0.001)$ in the STZ rats, whilst mean values of $17.9 \pm 0.8$ and $18.3 \pm 0.7 \mathrm{mg} / \mathrm{dl}(\mathrm{n}=30$ in both cases; $\mathrm{p}>0.69)$ were recorded on the same days in the normal animals. Last, at the onset of the present experiments, both the serum cholesterol and triglyceride concentrations were higher ( $p<0.005$ or less) in STZ rats than in normal animals, with respective mean values of $2.10 \pm 0.10$ and $1.80 \pm 0.10 \mathrm{~g} / 1$ ( $\mathrm{n}=40$ in both cases) in STZ rats, as distinct from $1.37 \pm 0.07$ and $1.43 \pm 0.05 \mathrm{~g} / \mathrm{l}(\mathrm{n}=30$ in both cases) in normal animals.

As a rule, there was little to distinguish, in the normal rats, between control and experimental animals. This is illustrated in Figs. 1, 2 and 3, which all refer to variables relevant to glucose homeostasis. Likewise, the data illustrated in Fig. 4 indicate that the sole significant effect of a Citrullus colocynthis L. extract, i.e. the defatted aqueous extract, was to oppose the gain in body weight otherwise recorded in the normal rats. The latter extract also decreased, in the normal rats, the wet weight of the liver, kidney, testes and epididymal fat. A modest beneficial effect was observed in the normal rats injected with the untreated aqueous extract, with a reduction of the AUC during the OGTT, of the epididymal fat weight, and of the serum cholesterol, triglyceride and glutamate-oxaloacetate transaminase concentration, when compared to the corresponding values found in the control normal rats.

In contrast to the situation found in normal rats, the daily administration of Citrullus colocynthis L. seed extracts often exerted beneficial effects in the STZ rats. For the purpose of comparison with the plant extracts, the experiments conducted in STZ rats also included the administration of glibenclamide. When compared to control STZ rats, the glibenclamide-injected STZ rats displayed, as expected, lower values of glycemia in the short-term experiments, as well as in the long-term experiments and during the OGTT. Moreover, the daily administration of glibenclamide prevented the increase in serum cholesterol concentration otherwise found in control STZ rats, and resulted in a higher epididymal fat weight than that found in the latter control STZ rats.

The beneficial effects of the plant extracts in the STZ rats included lower glycemia in the short-term experiments, longterm experiments and during the OGTT, lesser decrease in body weight, increase in epididymal fat weight, prevention of a progressive increase in serum cholesterol concentration and lower serum triglyceride concentration, when comparing the control STZ rats to those injected with a Citrullus colocynthis extract. When the relative magnitude of such beneficial effects was expressed according to the number zero (no significant effect), one (modest effect) and two (marked effect), the overall mean score for the seven variables under consideration in each 
group of experimental STZ rats yielded the highest value in the STZ rats injected with the untreated aqueous extract $(1.14 \pm 0.14)$ or $n$-butanol extract $(1.14 \pm 0.26)$ and the lowest value $(0.57 \pm 0.20)$ in the $S T Z$ rats injected with the defatted aqueous extract. Whilst the latter value was indeed significantly lower $(\mathrm{p}<0.05)$ than that recorded with the untreated aqueous extract, such was not the case for the in-between values found in the STZ rats injected with either the $\mathrm{H}_{2} \mathrm{O}$-methanol extract $(1.00 \pm 0.22)$ or ethyl acetate extract $(0.86 \pm 0.26)$. The difference observed in the STZ rats between the untreated and defatted aqueous extract is consistent with the findings made in the normal animals, in which the untreated aqueous extract also exerted selected beneficial effects, whilst the defatted aqueous extract caused several undesirable effects.

In conclusion, the present study extends to distinct extracts from Citrullus colocynthis L. seeds, and to a number of distinct biological variables, the view that further investigations dealing mainly with the identification of the most active components might eventually lead to the selection and development of a suitable agent in the perspective of the treatment of diabetic subjects, including both type-1 and type- 2 diabetic patients.

\section{Acknowledgements}

We are grateful to Professor A. Sener for help and hospitality in the Laboratory of Experimental Hormonology (Université Libre de Bruxelles), and to C Demesmaeker for secretarial help.

\section{References}

1. Zaree AB, Fallahhossini F, Sharifabady R, Norooz zadeh A, Emani $\mathrm{H}$ and Ghoshooni H: The effect of Citrullus colocynthis L. extract on preventing/reducing streptozotocin-induced diabetes in rat. Kawsar Med J 12: 13-20, 2007.

2. Benariba N, Djaziri R, Zerriouh BH, Boucherit K, Louchami K, Sener A and Malaisse WJ: Antihyperglycemic effect of Citrullus colocynthis seed aqueous extracts in streptozotocin-induced diabetic rats. Met Funct Res Diab 2: 71-76, 2009.

3. Jayaraman R, Shivakumar A, Anitha T, Joshi VD and Palei NN: Antidiabetic effect of petroleum ether extract of Citrullus colocynthis fruits against streptozotocin-induced hyperglycemic rats. Rom J Biol-Plant Biol 54: 127-134, 2009.

4. Al-Khateeb M, Dallak M, Al-Hashem F, Bashir N, Abbas M, Elessa R and Khalil M: In vivo, acute, normo-hypoglycemic, antihyperglycemic, insulinotropic actions of orally administered ethanol extract of Citrullus colocynthis (L.) schrab pulp. Am J Biochem Biotech 5: 118-125, 2009. 